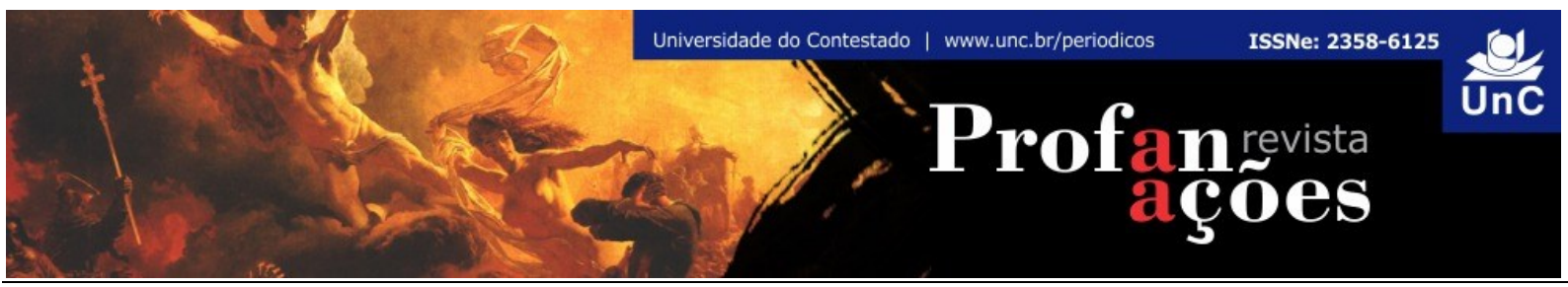

A QUATRO MÃOS COM MEDUSA: ESCRITAS DO MEDO NO (SOBRE) O ESTADO DE EXCEÇÃO

Tânia Sarmento-Pantoja ${ }^{1}$

RESUMO: O presente estudo concentra-se nas delimitações conceituais sobre arte de terror e arte da catástrofe com vistas a identificar pontos em comum. Desse modo toma como ponto de partida a reflexão sobre o medo considerando os diversos regimes estéticos, especialmente na literatura. A hipótese a ser movimentada é a de que o medo e seus efeitos perduram na arte envolvida com as dimensões da experiência por ele geradas, independente do regime de realidade que o objeto artístico possa adotar. Nesse percurso uma segunda hipótese indica que a literatura envolvida na especulação sobre o medo, quase sempre é uma literatura empenhada em narrar o terror, individual ou coletivo, mas sempre fundado na ameaça da perda, da petrificação ou paralisia.

Palavras-chave: Medo. Horror. Exceção. Catástrofe.

THE FOUR HANDS WITH MEDUSA: WRITINGS OF FEAR IN THE (OVER) STATE OF EXCEPTION

ABSTRACT: This study focuses on the conceptual boundaries of the art of terror and the art of catastrophe in order to identify common points. In this way it takes as its starting point the reflection on fear considering the various aesthetic regimes, especially in the literature. The hypothesis to be moved is that fear and its effects endures in the art involved with the dimensions of the experience generated by it, regardless of the regime of reality that the artistic object can adopt. In this way a second hypothesis indicates that the literature involved in speculation about fear is almost always a literature committed to narrating terror, individual or collective, but always based on the threat of loss, petrifaction or paralysis.

Keywords: Fear. Horror. Exception. Catastrophe

${ }^{1}$ Doutora em Estudos Literários pela Universidade Estadual Paulista Júlio de Mesquita Filho, Brasil. Professor Adjunto I da Universidade Federal do Pará, Brasil. E-mail: nicama@ufpa.br 


\title{
A QUATRO MÃOS COM MEDUSA: ESCRITAS DO MEDO NO (SOBRE) O ESTADO DE EXCEÇÃO
}

\begin{abstract}
Nós, que sobrevivemos aos campos, não somos verdadeiras testemunhas. Esta é uma idéia incômoda que passei aos poucos a aceitar, ao ler o que outros sobreviventes escreveram - inclusive eu mesmo, quando releio meus textos após alguns anos. Nós, sobreviventes, somos uma minoria não só minúscula, como também anômala. Somos aqueles que, por prevaricação, habilidade ou sorte, jamais tocaram o fundo. Os que tocaram, e que viram a face das Górgonas, não voltaram, ou voltaram sem palavras (LEVI, 1990, p.47).
\end{abstract}

Penso que o medo nos atrai e nos repele. Repele, primeiro, porque ao se instaurar o medo nos ameaça de apagamento, de suspensão: esse terror ancestral que nos alimenta o desejo de sobreviver. Essa atração reside no coração do medo por que em nós há também a insistência - mórbida - de (re) conhecer a face do Mal. Segundo, esse movimento baseado em repulsão e atração nos coloca diante do indecidível e talvez aí resida a fixidez que nos exaure ao sentirmos medo. Talvez seja essa inquietante dualidade o que levou a Medusa, a górgona, cujo simples olhar "era suficiente para que um homem se transformasse em pedra" (MARCH, 2015, p. 177), a ser uma das melhores alegorias do medo.

Esse ser, ao mesmo tempo, cativante e aterrador, possuía o poder de petrificar aquele que desafiava conhecer a sua face e, consequentemente, sua natureza singularmente híbrida e por isso mesmo monstruosa. Por esse motivo não conhecemos representações da Medusa que não carreguem a mistura de distintas formas. Meio humana, meio anfíbia, a Medusa apresenta essa relação gemelar entre o humano e o animal, a beleza e o terror, o encantamento e o assombro. Os cabelos em formato de serpentes mostram por sua vez a capilosidade das formas do horror com as quais podemos nos deparar e a violência brutal que costuma acompanhálas.

Olhar a Medusa, com sua "horrível cabeça feminina coroada de serpentes cuja visão produzia a morte" (AGAMBEN, 2008, p. 60), significa dispor-se a enfrentar a experiência do abalo, da dissolução. É, no caminho entre a tranquilidade e o caos, escolher o instante exato de um modo de morte: a experiência da paralisia, do corpo diante do abismo, porque, afinal, perdemos, senão tudo, pelo menos parte do que somos quando apanhados na experiência brutal do medo. Nela, tudo é suspenso: 
até a consciência do tempo se diluí na lividez que se instaura, pétrea, como nas vítimas do olhar medusiano. A ideia de que vamos perder algo ou vamos nos perder ao limite da imobilidade plena é o que fundamenta essa experiência.

Essa perda envolve principalmente a capacidade de simbolizar, de transformar em linguagem a própria experiência da petrificação. Nesse processo, evidencia-se como consequência imediata a suspensão da fala. O horror paralisa e suspende qualquer possibilidade de fala. Nesse sentido, o olhar medusiano nos lembra o testemunho de Primo Levi e a figura do muçulmano, que aqui se faz em epígrafe. Para Levi as verdadeiras testemunhas do Leger foram aquelas que viram as faces das Górgonas. No entanto, a experiência extrema do contato com a violência as transforma naquilo que Levi chama de "muçulmano", um não-homem, indivíduo que, sobretudo, se tornara presa de um catatonismo fatal. A referência que Levi faz às Górgonas é alegoricamente devedora dessa ideia de imobilidade decorrente do poder medusiano. Para Sandro Luís Bazzanela e Paulo Flávio de Andrade (2016, p.66):

O muçulmano é a figura medonha que nasceu nas sombras dos campos de concentração nazistas para ameaçar a dignidade humana. Uma figura privada da linguagem, de rosto, dignidade, abandonada pela humanidade, ignorada pelo ordenamento jurídico, aquém da simpatia dos deportados, despojada da vida e da morte, à mercê do escarro e do desprezo, tendo como única forma de resignação da sua ofensa à humanidade, a câmara de gás e o crematório.

A morte na forma de um catatonismo paralisante tem a mesma consequência: a ausência do testemunho dessa vítima que seria nas palavras de Levi o testemunho integral. Interessante notar que contra esse catatonismo há no testemunho de Levi o impulso a uma "fala sem parar", conforme evidencia Giorgio Agamben (2008, p. 26). Pensamos que mesmo sem garantir o testemunho integral essa verborragia pelo menos mantém a centelha da vida acesa para aquele que mesmo não sendo a testemunha integral, decide pela sobrevivência.

Uma ponderação pretendida nessas considerações é a de que há uma ancestralidade no medo: diante do que nos aterroriza tudo entra em colapso, o corpo, a consciência do tempo, do espaço, da alteridade. Perdemos o controle de qualquer linha no horizonte, não sabemos mais se estamos de pé ou de ponta a cabeça: sentimos-nos novamente fetos. Estagnados e mudos. De modo que se a 
vida é esforço em perseverar na existência; se a vida é fruição, então, medrar é também experimentar uma forma de perecimento, a suspensão do ser, em função da ameaça de perda.

Outra ponderação que lanço é a de que:

Por suas verberações a arte sobre o medo persiste como modo de pensar sobre o Mal. Como já antes o medo e seus efeitos perduram na arte envolvida com as dimensões da experiência por ele geradas, independente do regime de realidade que o objeto artístico possa adotar. Comprometida com a escatologia a literatura envolvida na especulação sobre o medo, quase sempre é uma literatura empenhada em narrar o terror, individual ou coletivo, mas sempre fundado sobre essa base ontológica: a ameaça da perda e o laboratório de uma espécie de petrificação ou paralisia. Resistir a essa ameaça pode ser a diferença entre sucumbir e sobreviver. Mas essa luta é sempre sufocante e agônica, pois essa literatura que narra o terror se faz atravessada pela presença avassaladora da violência. salientado as formas artísticas pensam sobre o medo a partir dos mais diversos regimes estéticos, especialmente se a perda e a paralisia, as duas grandes chaves do medo, constituem a matéria fundamental do objeto artístico, tal como se apresentam em duas formas narrativas: as narrativas de horror e as narrativas da catástrofe. Por esse motivo a hipótese que move este estudo é a de que é possível observar semelhanças redundantes em ambas as formas, especialmente no que diz respeito às pulsões de morte que emanam dos personagens que representam o Mal.

Para dar conta dessa possibilidade comparativa proponho alguns pressupostos constituintes da narrativa da catástrofe, em uma configuração diferenciada daquela mais popular - as narrativas hollyoodianas. Para fazer o paralelo com a narrativa de horror, tomo as categorizações conforme pensadas por Noëll Caroll (1990). Como limite analítico, procuro direcionar algumas digressões sobre o monstro nesse gênero em particular a fim de traçar alguns pontos de contato entre essas formas de manifestação do horror. Esses pontos em comum podem ser importantes ao pesquisador interessado em produções literárias cujos escritores escrevem a quatro mãos com a Medusa. 


\section{A arte de horror ou o horror na arte}

Em The Philosophy of Horror, Noëll Caroll (1990, p.8) considerando o raciocínio de Aristóteles presume que o gênero horror é projetado para produzir um efeito emocional. Nesse percurso Carroll tenta mostrar como as estruturas, características, imagens e figuras do gênero são dispostas de maneira a causar a emoção que chama de arte de horror (art-horror) ou horror artístico. Para Carroll o horror enquanto gênero artístico e literário cristalizou-se a partir da época da publicação de Frankenstein e persistiu através dos romances e peças de teatro do século XIX e na literatura, nos quadrinhos e filmes do Século XX e XXI. Porém, o horror não está presente apenas nesse período. Já na Antiguidade Clássica, é possível observar, por exemplo, a história do lobisomem no Satyricon, de Petronius, e ainda a de Licaon e Júpiter nas Metamorfoses de Ovídio. Na época medieval destacam-se os topos das danças medievais macabras e caracterizações de experiências infernais, como na Visão de São Paulo, na Visão de Túndalo e n'O Inferno de Dante. Nesse trajeto, na iconografia temos ainda Os Sete Pecados Capitais, de Bosch e O Juízo Final, de Fra Angelico, em que essa estrutura das visões permanece presente.

De acordo com Carroll o limite entre a história de horror e a mera história com monstros, tais como ocorre em narrativas míticas, são as atitudes e emoções manifestas por personagens que não são monstros ao se depararem com os monstros. Em obras de horror os seres humanos veem os monstros como anormais, como distúrbios da ordem natural. Por outro lado, nos contos de fadas, os monstros fazem parte da organização daquele universo e como tal ainda que pareçam anormais aos olhos do leitor/expectador são absolutamente comuns no mundo em que habitam. Por exemplo, em "As Três Princesas de Brancolandia", narrativa pertencente à coletânea intitulada O Fabuloso Livro Vermelho, segundo dos doze volumes de contos de fadas compilados por Andrew Lang, um rapaz é atormentado por um troll de três cabeças. No entanto, é importante observar que essa criatura não é menos incomum do que leões que ele havia encontrado anteriormente. Por outro lado, de acordo com Carroll (1990, p.16), uma criatura como Chewbacca, pertencente ao universo da saga Star Wars é apenas mais um dentre os personagens heróicos. Mas em outras produções, como no filme Grito de Horror 
(1981), direção de Joe Dante, um personagem com aparência semelhante a Chewbacca desencadeia o pavor e é encarado com grande repulsa pelos personagens humanos.

Essas ponderações levam Carroll a propor que grifos, quimeras, basilísticos, dragões e outras criaturas são incômodas e temíveis, contudo, nas cosmologias em que estão acomodados existem naturalmente. Não há no interior desses universos qualquer questionamento sobre a viabilidade da natureza de tais personagens. Não é exatamente essa estrutura que delimita a condição de sua monstruosidade. Isso porque os monstros, e particularmente os monstros do gênero horror, ao contrário, são reconhecidos como seres que por alguma razão violam as normas e as propriedades ontológicas assumidas pelos personagens humanos positivos na história. Desse modo, é possível depreender que por mais que um personagem ou uma circunstância sejam incomuns - ou mesmo com aparência não humana - essa condição não gera necessariamente a repugnância, que é a marca do monstro no gênero horror. Cito Carroll (1990, p. 16):

em exemplos de horror, parece que o monstro é um ser extraordinário no
nosso mundo ordinário, enquanto nos contos de fadas o monstro é uma
criatura ordinária num mundo extraordinário. E a condição extraordinária
desse mundo - e a marca de sua distância em relação ao mundo ordinário
que habitamos - é muitas vezes sinalizada por fórmulas como 'era uma vez'.

Ao acompanhar o raciocínio de Carroll é-me possível argumentar, então, que a repugnância causada pela aparência ou comportamento dos personagens monstruosos nas ficções de terror parece ter a função de fazer os leitores/expectadores desenvolverem repulsa ao monstro e empatia em relação as suas possíveis vítimas, na medida em que valores, perspectivas e situações vivenciadas pelos personagens não considerados monstros de certa forma espelham, ainda que em parte, valores, perspectivas e situações dos receptores (leitores/expectadores) do objeto artístico.

De fato, para Carroll (1990, p.18), essa é uma das características chaves do gênero horror: os leitores/expectadores constroem respostas ao monstro que convergem para (mas não exatamente duplicam) as das vítimas e essas respostas podem compreender certa sintomatologia, como tremor, asco, náusea, retraimento, paralisia. Vale destacar que o pacto ficcional não deixa de funcionar nesse processo, 
muito pelo contrário, pois assim como os personagens, uma vez na condição de leitores/expectadores, avaliamos o monstro como um tipo horrível de ser, ainda que inversamente aos personagens, não acreditemos na sua existência.

Uma característica proeminente nesse processo é a instituição da náusea. De acordo ainda com o raciocínio de Carroll $(1990$, p.22) certas criaturas são tão fisicamente horríveis e repulsivas, que muitas vezes provocam náuseas nos personagens com quem estabelecem algum tipo de contato. Alguns, além de apresentarem uma aparência apavorante possuem condições fisiológicas que no mínimo ferem consideravelmente os limites da tolerância ou de pudores culturais desenvolvidos por seres humanos, ao produzirem excrementos, fluídos repugnantes ou gazes putrefatos. Via de regra essa associação de elementos repugnantes representam uma violação física e psíquica tão profunda que frequentemente produz em outros personagens a certeza de que o simples contato com o monstro pode ter um resultado aniquilador.

A insuportabilidade evidenciada no contato com esses elementos repugnantes podem ser compreendidos em função da abjeção que provocam. Em seu ensaio The Powers of Horror (1982) Júlia Kristeva busca nos mostrar os mecanismos da abjeção, categoria que avalio ser fundamental para a compreensão de formas artísticas que elegem o medo como base de suas especulações. Para ela o abjeto é, sobretudo, uma condição que podemos opor a outras condições e manifesta-se de maneira plural: o asco provocado pelo contato com o cadáver ou o conteúdo purulento de uma ferida, os fluidos corporais, mesmo certas atitudes não previstas em um determinado código cultural capazes de ser entendidas como violações radicais da vida, podem causar abjeção.

Os fluidos corporais, os excrementos, as impurezas de todo tipo são suportados com grande esforço e constituem limites para a convivência com tudo aquilo que representa ou implica uma escatologia. De fato, Kristeva observa que o abjeto tem por atributo fragilizar ou quebrar fronteiras, ao colocar sob suspeita a suposta integridade do ser - e do mesmo modo os signos estabelecidos por sua cultura relativos a essa condição. Essa dimensão do abjeto pode repercutir em distintos materiais artísticos através da representação do mau desempenho e desequilíbrio dos sujeitos e da sociedade. 
Toda essa repugnância resulta e ao mesmo tempo evoca o contato com o incomum, o estranho, o incompreensível, e consequentemente, o inaceitável e o ameaçador. Em outras palavras o repugnante não é assimilável e por sua vez o que não é assimilável termina por ser rejeitado justamente por parecer irracional e, por conseguinte, ameaçador. E desse modo nos coloca diante do medo. O medo sem dúvida nos aterroriza porque aquilo que nos motiva o medo, o que nos inculca a paralisia, ao mesmo tempo nos obriga a olhar - e a reconhecer - a vulnerabilidade $e$ o irrevogável assujeitamento que nos tornam descontínuos e imobilizados. Prova disso são as reações físicas a essa experiência, traduzíveis em contração muscular, tensão, sudorese intensa, boca seca, pelos eriçados, calafrio, formigamento, tremor, paralisia momentânea, grito involuntário etc. Todos reflexos motivados por apreensão ou respostas de alerta fisicamente acentuados. A propósito Carroll (1990, p.24) nota que o termo "horror" deriva do latim "horrere" - que significa ficar de pé (como os pelos eriçados quando sentimos medo), desse modo a origem etimológica do termo já aponta para uma manifestação física afinada com as agitações fisiológicas sentidas nessas situações.

Segundo ainda as proposições de Carroll, como um complemento à náusea pode também haver a manifestação de uma impureza de matiz patológica por parte do monstro. Nesse caso, além do monstro provocar a repugnância ele também pode ser o veículo para o contágio de algo a ser funesto para a vítima, como veremos mais adiante. Vale ressaltar mais uma vez que todos esses critérios convergem sempre para o princípio da ameaça. Os componentes que constituem a ameaça derivam do fato de que os monstros encontrados em histórias de horror são uniformemente e radicalmente perigosos ou pelo menos devem parecer dessa forma. Se por alguma razão deixam de ser ameaçadores, também não são mais repugnantes.

O receio e a náusea frente à possibilidade do contágio derivam por sua vez do critério da impureza prevalecente no monstro da narrativa de horror. Vale mencionar que Nöel Carroll, e como ele, Fernando Costa e Christofer Pallu, apontam a natureza híbrida do monstro como base para esse critério, cujo argumento de fundo reside na transgressão de esquemas de categorização: 
Monstros de horror são impuros na medida em que se mostram como categoricamente intertisiciciais, contraditórios, incompletos - eles desafiam distinções habitualmente aceitas como vivo/morto, animado/inanimado, parte/todo, orgânico/inorgânico etc, daí provem seu caráter aversivo. Ao desestabilizarem categorias que constituem nossos (pretensos) esquemas conceituais, os monstros instaciam violações da ordem natural ou de um conceito cientificamente aceito de natureza (COSTA; PALLU, 2014, p. 194).

Desse modo, o critério da impureza é o responsável pela regularidade com que as representações artísticas das experiências de horror incluam a referência a antipatia, a repugnância, a náusea, a aversão física, a abominação, e assim por diante, enfim, tudo o que pode ser caracterizado como resultante da percepção de que é algo nocivo justamente por ser impuro ou incomum. Carroll (1990, p.28) ainda alerta que o critério da impureza no gênero horror freqüentemente associa uma determinada condição de um ou mais personagens repugnantes a enfermidades ou circunstâncias que evidenciam que tal personagem é capaz de gerar alguma forma de contagio pernicioso, se o contato for materializado, como, por exemplo, o vampirismo em Dracula, de Brian Stoker e em outras produções com a mesma temática; ou como na mitologia da franquia Alien é explicado o surgimento do primeiro xenomorfo, em Prometheus (2012), de Ridley Scott.

Sintomático que nessa perspectiva o monstro se faça constantemente parasita. Em uma dicção com o estudo de Michel Serres, Davi Rodrigues dos Santos (2013, p.29) especula que o parasita "introduz sempre distúrbios no corpo do hospedeiro e assegura que existe sempre alguma perda por parte do mesmo". Para Santos, sendo o Alien um híbrido de corpo orgânico e tecnológico, na condição de parasita funciona de certa forma como alegoria do poder tecnológico, desse modo representando "simultaneamente, uma força totalitária, penetrante e de perda total da autonomia humana" (SANTOS, 2013, p.30). Esse aspecto é muito importante para certos argumentos que desenvolvo mais adiante. Com essa perspectiva cito mais uma vez Santos (2013, p.30), ao analisar as configurações do parasita em Prometheus:

Ele é exposto em vários níveis, ou seja, o filme começa com a apresentação de algo que pode ser entendido como a conceção da vida humana (o seu ADN) através de microparasitas alienígenas. Este episódio evoca o possível momento da criação e desenvolvimento de todos os seres. Em segundo lugar, Scott apresenta o parasita tradicional, ou seja, o modelo predatório no qual os organismos alienígenas disputam os seus recursos. Por último, e 
mais importante, o filme apresenta-nos o parasita regulador, o destruidor do excesso, ou seja, aquele cujo principal objetivo é a própria destruição do ser criado - o ser humano. Assim, as ações parasitárias neste filme podem ser interpretadas mediante um modelo económico clássico da escassez, isto é, onde o parasitismo segue um modelo predatório que tenta equilibrar o ecossistema. Porém, por outro lado, Prometheus também pode apresentar uma habitação parasitária na forma de arma de destruição massiva.

Esses aspectos além de não serem circunstanciais apontam para o primado da abjeção em narrativas manejadoras do medo. Júlia Kristeva chama atenção para o fato de que uma vez instaurada a abjeção - produto da repugnância - há a necessidade de reagir a tal condição e o trabalho com a imaginação é importante para a expressão dessa necessidade. Considerando o que diz Kristeva é possível entender que a linguagem utilizada para dar conta da abjeção pode ser marcada pela presença da violação, sendo essa condição manifesta tanto na ordem da sintaxe, quanto do léxico. Por sua vez a experiência do medo nos coloca de um só golpe frente ao limite entre a segurança e a ameaça. Como a abjeção geralmente se faz presente nas experiências que envolvem o medo a linguagem do medo pode se fazer sulcada dos resíduos da abjeção.

As indicações de Kristeva favorecem pensar a abjeção, bem como os legados da natureza repugnante, aterrorizadora e parasitária do monstro, a ameaça da perda e o laboratório de uma espécie de petrificação ou paralisia, como constitutivas de possíveis pontos de contato entre a narrativa de horror, ou mais propriamente a arte de horror - como pensa Carroll - e a narrativa da catástrofe. Ou arte da catástrofe.

\section{A narrativa da catástrofe e a catástrofe na arte}

Antes de continuar é preciso, porém, definir que entendo a arte da catástrofe como o espaço de representação da vida ao avesso e, nesse sentido, acompanho o pensamento de Márcio Seligmann-Silva, cuja compreensão sobre a catástrofe se faz a partir das ideias de "desabamento" e "desastre" contidas no termo em grego "catastrophe". Segundo Seligmann-Silva $(2000$, p.8) a catástrofe:

é, por definição, um evento que provoca um trauma, outra palavra grega que quer dizer 'ferimento'. 'Trauma' deriva de uma raiz indo-européia com dois sentidos: 'friccionar, triturar, perfurar'; mas também 'suplantar', 'passar através'. Nesta contradição - uma coisa que tritura, que perfura, mas que, ao mesmo tempo, é o que faz suplantá-la, já se revela, mais uma vez, o 
paradoxo da experiência catastrófica, que por isso mesmo não se deixa apanhar por formas mais simples de narrativa.

Em grego "catástrofe" também é "acontecimento lastimoso e funesto" ou "grande desgraça". Enrico Louis Quarantelli (1998) afirma que "desastre" e "catástrofe" não são termos sinônimos. Haveria uma diferença entre as duas categorias relacionadas à magnitude do fenômeno que elas definem: enquanto o "desastre" significa um acontecimento terrível, com possibilidade de haver perdas humanas, mas localizado em uma comunidade limitada e no interior de um determinado espaço-tempo, a "catástrofe", por sua vez significaria um impacto de enorme magnitude sobre os serviços essenciais, o patrimônio material e o ambiente, envolvendo grade número de perdas e/ou dispersão humanas, ou mesmo o risco de/ou a extinção da espécie. Para entendermos melhor a economia da narrativa da catástrofe basta que lembremos de alguns exemplos na cinematografia do gênero em seu modelo mais popular, aquele em que a natureza é a responsável pelo estado catastrófico, como no filme The Day After Tomorrow (O dia depois de amanhã), produzido em 2004, com direção de Roland Emmerich.

Nesse modelo há sempre a presença de um mundo desregulado ante a iminência da destruição total, condição que por sua vez gera grande abalo comunitário ante a ideia de que o mundo tal como o conhecemos não existirá mais. $\mathrm{Na}$ cinematografia hollywoodiana é comum que ao final da narrativa um ou mais indivíduos humanos sejam os responsáveis por salvar a espécie e trazer o mundo conhecido de volta, mesmo que em condições precárias e mesmo que isso represente o sacrifício do de um indivíduo ou de um grupo na condição de "salvador da pátria". Uma vez o mundo conhecido, ordinário e comum destruído o que nos restaria na arte da catástrofe seria um mundo descontínuo (THOM, 1985) e marcado pela anomia. Trago aqui uma ampliação desse paradigma, já proposto em outro estudo:

Guerras, revoluções e conflitos armados podem provocar impactos gigantescos sobre os serviços essenciais e o patrimônio material, ambiental e cultural. O concentracionismo, as perseguições, os genocídios e os massacres são igualmente grandes motivadores da dispersão humana e mesmo da extinção - não propriamente da espécie humana - mas de determinadas etnias, segmentos religiosos ou políticos. Em todo caso, a Catástrofe sempre se encontra no interior da exceção e por isso deve ser compreendida como a precipitação da experiência para fora da norma e do 
familiar. Nesses termos, Catástrofe suscita, pela extinção do comum, uma experiência partida (SARMENTO-PANTOJA, 2014, p.167).

Penso ser essa experiência partida uma das principais chaves da arte da catástrofe. Nessa definição, tal como o conceito de abjeção é substancial para compreender alguns mecanismos presentes na arte de horror, da mesma forma o conceito de exceção é fundamental para pensarmos a arte da catástrofe, por ser a exceção um dos principais devedores dessa experiência partida. Exceção aqui pensada como parte do conceito de "estado de exceção" conforme nos elucida Giorgio Agamben (2004): no interior do Estado soberano o estado de exceção emerge como medida de necessidade à segurança do Estado. Nas palavras de Agamben o "estado de exceção não e uma ditadura (constitucional ou inconstitucional, comissária ou soberana), mas um espaço vazio de direito, uma zona de anomia em que todas as determinações jurídicas - e, antes de tudo, a própria distinção entre público e privada - estão desativadas" (2004, p.80).

No estado de exceção a vida, e nela tudo o que a legisla, deve se adequar aos interesses ditos excepcionais. A forma de vida implicada nesse processo é a da vida nua, cujo fundamento é a violência emergente de um Soberano ou de algo ou alguém que representa uma soberania e exerce poder sobre essa vida. A suspensão das determinações jurídicas, em prol das necessidades ou mesmo da cultura do estado de exceção, geram a vida nua e esta por sua vez é a condição fundamental para a emergência da catástrofe. A vida nua se apresenta desse modo também como outra condição devedora da arte da catástrofe.

Tomo essa condição como limite analítico, na medida em que procuro me deter especialmente em narrativas da catástrofe, fundadas na especulação problematizadora do estado de exceção, com evidentes figurações da vítima do estado de exceção e do perpetrador, este aqui entendido como todo agente fiscalizador e punitivo pertencente ao braço armado, mais particularmente dos regimes ou condições de exceção. Nesse sentido, proponho ser o perpetrador fundamental instrumento de violação e imolação da alteridade. Sendo uma extensão do tirano, mas ao mesmo tempo em muito diferenciado dele, o perpetrador é o responsável direto pelo funcionamento da máquina repressiva. Nos regimes de exceção ora é o policial que investiga e colhe informações sobre os opositores do 
regime, ora é a autoridade responsável por planejar e conduzir as ações repressivas, ora é o torturador que executa as sevícias, os desaparecimentos e os assassinatos.

Com tais condições o perpetrador é um personagem importante, quiçá indispensável, na presença de um Estado falido na garantia dos direitos fundamentais do homem ou porque se encontra ausente da gestão pública, ou porque o próprio Estado funda e mantém a violência através dos dispositivos jurídicos do estado de exceção. Em ambas as possibilidades o perpetrador é o responsável direto pelo maquinário da tortura e da morte tornando-se a mente e o corpo, que ao modo de uma arma, investiga, persegue, captura, despoja, encarcera, tortura, elimina e, finalmente, desaparece com os corpos das vítimas. Nesse processo, o corpo do perpetrador funciona como extensão jurídica e executiva do Estado e do arbítrio de quem decide o estado de exceção.

O conto "O jardim das Oliveiras, de Nélida Piñon, que compõe a coletânea de contos No calor das coisas (1980) é um bom exemplo do que estamos falando. $O$ conto nos relata o terror agônico de um protagonista narrador que é obrigado a encarar a figura do perpetrador, representado nessa narrativa por torturadores, no contexto das ações repressivas da ditadura civil e militar de 1964.

Esse conto de Piñon realça a experiência da paralisia de uma maneira muito peculiar. O protagonista é pela segunda vez apanhado por seus algozes a fim de passar por novo interrogatório e, portanto, ele sabe o horror que o aguarda. Com base no recurso ao flashback o personagem rememora as torturas sofridas anteriormente, bem como o profundo remorso que o acomete por ter delatado um companheiro de luta. Desse modo, o relato compõe-se da mistura vertiginosa do receio em voltar a experimentar novamente os sofrimentos da tortura, o sentimento de culpa por ter se tornado delator e a possibilidade de não resistir aos sofrimentos e voltar a entregar outro companheiro de militância. Estruturalmente, a narrativa do conto apropria-se da forma do testemunho especialmente em decorrência da perspectiva narrativa assumida: a da vítima, extremamente sujeita, portanto, à experiência do medo. 


\section{Arte de horror e arte da catástrofe: o monstro e as projeções da violência exorbitante}

São vários os pontos de contato entre a arte de horror e a arte da catástrofe, das quais destaco as expressões da violência imoladora (torturas, humilhações); a presença onipotente de algo ou alguma coisa que representa o Mal (o monstro/o tirano); o nojo; as ilações entre o sublime e o feérico. Todas essas condições apontam incondicionalmente para as fulgurações do medo, especialmente para os efeitos de ameaça, aniquilamento ou assujeitamento.

Um importante aspecto no laboratório do medo nessa literatura é a figura do monstro ou da monstruosidade. Nesse percurso, não estou falando tão somente do monstro clássico, proveniente de uma mitologia ou de uma determinada tradição ou do monstro da narrativa de horror, marcado pelo princípio da impureza. Ganha espaço aqui também o monstro da narrativa da catástrofe, tão humano quanto a vítima da experiência traumática geradora do medo. $\mathrm{E}$ em certas situações é monstruosa também a máquina geradora do sofrimento dessa vítima.

Nesse sentido, o monstro da narrativa da catástrofe afasta-se do imperativo da impureza do monstro da narrativa de horror, pois sua constituição enquanto personagem nem resulta de uma natureza impura e nem possui aparência física incomum. Exceto narrativas da catástrofe que expressam o perpetrador na forma de uma alegoria do terror o "monstro" nessas narrativas é tão fisicamente humano quanto qualquer um de nós. Contudo, mesmo que sejam personagens com aparência comum as violações que promovem não deixam de ferir propriedades ontológicas assumidas pelos personagens humanos positivos na história. Ferem, especificamente, e de maneira radical princípios fundamentais do estado de direito no interior da exceção, ao se apropriarem dos corpos alheios com o intuito de submetê-los à violação sórdida. Nesse caso a natureza incomum e excepcional desse monstro reside menos no corpo do monstro - ainda que aos olhos da vítima o corpo do monstro possa espelhar signos da abjeção inerente a si mesmo - mas, sobretudo, nos atos violentos. Atos extremamente vis, capazes de macular a condição humana.

Nesse sentido, em narrativas da catástrofe o perpetrador é o agente das monstruosidades, especialmente por seu comportamento repugnante e em função 
das consequências abjetas das violações deferidas contra suas potenciais vítimas, tornando-se desse modo o grande protagonista da anomia enquanto violador do corpo do outro. Ao expor sua vítima às condições humilhantes e sofrimento físico ocasionados por torturas físicas e psíquicas o perpetrador das narrativas da catástrofe tal qual o monstro da narrativa de horror igualmente evoca essa sofisticada ordem que associa medo, vulnerabilidade e abjeção, a partir da experiência extrema envolvendo a violência subjugadora da alteridade. Ele é a fonte imediata - mas não a única - da desordem e do caos e em seus gestos muito mais do que em seu corpo se concentra de forma potente a ameaça à segurança, à vida de outrem. Nesse sentido, é o gesto monstruoso ou, em outras palavras, a monstruosidade cometida por esse personagem, a fonte do horror em narrativas da catástrofe marcadas pelo estado de exceção.

Para tentar elucidar melhor essa dimensão, tomo como inspiração a figura do monstro humano tal como se encontra no pensamento de Michel Foucault (2001, p.69), definido pela associação entre o proibido e o impossível: "o que define o monstro é o fato de que ele constitui em sua existência e em sua forma, não apenas uma violação das leis da sociedade, mas uma violação das leis da natureza". Desse modo, não basta transgredir a lei: é necessário atingir de maneira radical a previsibilidade da determinação jurídica, excluindo-a da cena em que se dá o ato violador. Nesse ponto é importante a dicção entre Focault e Agamben, pois se o perpetrador age em nome do estado de exceção e dele deriva sua soberania, essa relação com a lei é ainda mais problemática, pois ele se encontra dentro e fora da lei: dentro da lei excepcional do estado de exceção, mas fora do Direito.

Para finalizar, essa ameaça à vida, geralmente concentrada na violação do corpo do outro, gera abjeção, bem como os legados da natureza repugnante e aterrorizadora daquele que está na condição de violador. Essa abjeção se estende à dramatização da linguagem: na escrita sobre essa forma de violência o encontro entre a vítima e o violador é, sobretudo, marcado pela crueldade enquanto a ameaça da perda e o laboratório de uma espécie de petrificação ou paralisia se fazem constantes e prenunciam o argumento de que embora ocorram diferenças em relação ao monstro violador da arte de horror, podemos pensar que ao modo de uma metonímia, o violador da arte da catástrofe também exerce uma força parasitária sobre suas vítimas. Obviamente, não se trata aqui da relação parasitária 
tradicional em que um parasita preda sua vítima a fim de que possa de alguma forma alimentar-se ou reproduzir-se, como condição para prover a própria sobrevivência, mas, sobretudo, o "parasita regulador" cuja função é, fundamentalmente, esgotar ou destruir o que é considerado excedente no interior de uma "máquina" de guerra sádica e devoradora. É dessa forma que o perpetrador olha o rebelde, sua vítima: como excedente a ser expurgado em função de uma guerra a ser vencida.

Sem deixar de lançar um olhar visceral em direção ao monstro, narrativas de horror e narrativas da catástrofe, cada uma delas a seu modo, nos mostram que nos tornamos não-homens diante da medusa e isso significa que o medo é condição redutora da humanidade tanto para quem o experiência, quanto para quem o evoca como instrumento de poder.

\section{REFERÊNCIAS}

AGAMBEN, Giorgio. Estado de exceção. Tradução de Iraci D. Polleti. São Paulo: Boitempo, 2004.

. O que resta de Aushwitz: o arquivo e a testemunha. Tradução de Selvino J. Assmann. São Paulo: Boitempo, 2008.

BAZZANELLA, Sandro Luiz; ANDRADE Paulo Flavio de. Para uma ética e uma política que vem: a figura do muçulmano nos campos de concentração.

Profanações, n. 2, p. 65-82, jul./dez. 2016.

CAROLL, Noëll. The Philosophy of Horror: paradoxes of the heart. New York/Londres: Rotledge, 1990.

COSTA, Fernando; PALLU, Christofer. Da impureza como categoria política. In:

GARCIA, Demian (org). Cinemas de Horror. São José dos Pinhais: Estronho, 2014.

FOUCAULT, Michel. Os anormais. Tradução de Eduardo Brandão. São Paulo: Martins Fontes, 2001.

LEVI, Primo. Os afogados e os sobreviventes. Tradução de Luís Sérgio Henriques. Rio de Janeiro: Paz e Terra, 1990.

KRISTEVA, Júlia. The Powers of Horror. New York: Columbia, 1982.

MARCH, Jenny. Mitos clássicos. Tradução de Maria Alice Máximo. Rio de Janeiro: Civilização Brasileira, 2015. 
QUARANTELLI, Enrico Louis. (ed.) What is a disaster? Londres e Nova York: Routledge, 1998.

SARMENTO-PANTOJA, Tânia. Catástrofe: manual do usuário. In: SARMENTOPANTOJA, Augusto; SARMENTO-PANTOJA, Tânia, UMBACH, Rosani. Estudos de Literatura e Resistência. Campinas: Pontes, 2014.

SELIGMANN-SILVA, Márcio. A história como trauma. In: NESTROVSKI, Arthur; SELIGMANN-SILVA, Márcio (Org.). Catástrofe e representação. São Paulo: Escuta, 2000.

SANTOS, Davi Rodrigues dos. A invasão de Prometheus: Habitantes parasitários na produção artística. Disponível em: <http://s3.amazonaws.com/ academia.edu.documents/34697687/17_2.pdf?AWSAccessKeyld=AKIAIWOWYYGZ 2Y53UL3A\&Expires=1497724001\&Signature=mlyM\%2BUmOQBOgPT6wQ0WHejU R5nY\%3D\&response-content-disposition=inline \%3B\%20filename\%3 DA_invasao_de_Prometheus_Habitantes_paras.pdf $>$.

THOM, Renè. Parábolas e Catástrofes. Lisboa: Publicações Dom Quixote, 1985.

Artigo recebido em: 01/07/2017

Artigo aprovado em: 15/11/2017

Artigo publicado em: 18/12/2017 